SOI: $\underline{1.1 / \text { TAS }}$ DOI: $10.15863 /$ TAS

\section{International Scientific Journal Theoretical \& Applied Science}

\author{
p-ISSN: 2308-4944 (print) e-ISSN: 2409-0085 (online) \\ Year: 2017 Issue: $04 \quad$ Volume: 48
}

Published: $30.04 .2017 \quad$ http://T-Science.org
Sergey Alexandrovich Mishchik

Associate Professor, Candidate of Pedagogical Science,

Academician of International Academy TAS, Assistant professor Department of Physics, State Maritime University Admiral Ushakov, Russia sergei_mishik@mail.ru

SECTION 21. Pedagogy. Psychology. Innovation in Education.

\title{
SYSTEMIC HYDRAULIC PROBLEMS OF APPLIED PHYSICS MARITIME FLOT OF PEDAGOGOMETRIC ANALYSIS
}

Abstract: The basic principles of the system of hydraulic problems in applied physics Navy pedagogometric analysis of the formation of mathematical models of learning activities about the nature of achieving the criteria of life, cycling, systemsness and phasing, which form a basic cell of the educational space, as well as prima nenie twelve pointed star Ertsgammy relatively presentation ertsgamming principle which determines the foundations pedagogometric through forming substantive methods of hyper-space professional life, psychological and educational activity theory, psycho-pedagogical system analysis and the theory of the formation of mental actions.

Key words: pedagogometric, vital activity, cyclicity, system, phase, star Erzgammy, hydraulics, applied physics, marine fleet.

Language: Russian

Citation: Mishchik SA (2017) SYSTEMIC HYDRAULIC PROBLEMS OF APPLIED PHYSICS MARITIME FLOT OF PEDAGOGOMETRIC ANALYSIS. ISJ Theoretical \& Applied Science, 04 (48): $128-136$.

Soi: http://s-o-i.org/1.1/TAS-04-48-21 Doi: crostef https://dx.doi.org/10.15863/TAS.2017.04.48.21

УДК 372.851

\section{СИСТЕМНЫЕ ГИДРАВЛИЧЕСКИЕ ЗАДАЧИ ПРИКЛАДНОЙ ФИЗИКИ МОРСКОГО ФЛОТА ПЕДАГОГОМЕТРИЧЕСКОГО АНАЛИЗА}

Аннотация: Рассмотрены основные принципы построения системных гидравлических задач прикладной физики морского флота педагогометрического анализа при формировании математических моделей учебной деятельности относительно характера достижения критериев жизнедеятельности, цикличности, системности и этапности, которые образуют базисную ячейку образовательного пространства, а также применение двенадиати конечной звезды Эригаммы относительно представления принципа эригаммности, который определит основы педагогометрики через формообразование предметными методами гиперпространства профессиональной жизнедеятельности, психологопедагогической теории деятельности, психолого-педагогического системного анализа и теории формирования умственных действий.

Ключевые слова: педагогометрика, жизнедеятельность, ичикличность, системность, этапность, звезда Эригаммы, гидравлика, прикладная физика, морской флот.

\section{Introduction}

Представление системных гидравлических задач прикладной физики морского флота педагогометрического анализа связывается с решением проблемы формирования математических моделей учебной деятельности относительно характера достижения критериев жизнедеятельности, цикличности, системности и этапности, которые образуют базисную ячейку образовательного пространства, а также применение двенадцати конечной звезды
Эрцгаммы относительно представления принципа эрцгаммности, который определит основы педагогометрики через формообразование предметными методами гиперпространства профессиональной жизнедеятельности, психолого-педагогической теории деятельности, психолого-педагогического системного анализа и теории формирования умственных действий.

Это проявляется в совершенствовании базы данных прикладных профессиональных задач выделенной профессиональной деятельности на 
морском флоте. Построенные одновременно математические модели учебнопрофессиональной деятельности связываются с: базисной звездой Эрцгаммы гиперпространства жизнедеятельности (Е1); базисным целостносистемным циклом жизнедеятельности (Е2); базисной звездой Эрцгаммы системного анализа (E3); базисным проявлением двенадцати этапов и форм познавательного гиперпространства жизнедеятельности относительно образовательного процесса (E4).

Совершенствование заданой базы данных педагогометрических моделей эрцгаммного анализа образовательных объектов с признаком базисно-нормативной эрцгаммности, независимо от целевого назначения, выполняет собственную функцию психолого-математического представления

\section{Materials and Methods}

Системные гидравлические задачи прикладной физики морского флота отражают целостно-системное моделирование основных элементов транспортных объектов. При этом возникает ориентация на единство базисных характеристик предметных и исполнительных условий относительно предмета содержания и способа его реализации. Рассматриваются: физические свойства жидкости и газа, основы гидростатики, кинематика и динамика жидкости, гидравлический расчет истечения, гидравлический удар в трубах, гидравлический расчет трубопроводов гидросистем, основы теории подобия и моделирования на морском флоте.

В процессе решения системных задач динамической прикладной физики морского флота необходимо применять основные положения теории деятельности, системного анализа и теории формирования интеллекта.
Системный анализ предполагает выполнение последовательности системных аналитических действий: выделить объект анализа - гидравлическую задачу прикладной физики морского флота (ГЗПФМФ) как систему; установить порождающую среду ГЗПФМФ; определить уровни анализа ГЗПФМФ; представить целостные свойства ГЗПФМФ относительно пространственных, и временных характеристик и их комбинаций; выделить структуру уровня анализа ГЗПФМФ; установить структурные элементы уровня анализа ГЗПФМФ; определить системообразующие связи данного уровня анализа ГЗПФМФ; представить межуровневые связи анализа ГЗПФМФ; выделить форму организации ГЗПФМФ; установить системные свойства и поведение ГЗПФМФ.

\section{Задача 1}

При гидравлическом испытании участка судового трубопровода диаметром $\mathrm{d}=200$ мм и длиной 250 м давление в трубе было повышено до 3 МПа. Через час давление снизилось до 2 МПа. Сколько воды вытекло через неплотности системы?

Ответ: 3,93 л

\section{Задача 2}

Сколько кубометров воды будет выходить из судового отопительного котла, если за час в отопительный котел поступило $50 \mathrm{~m}^{3}$ воды при температуре $70{ }^{\circ} \mathrm{C}$, а затем температура воды повысилась до $90^{\circ} \mathrm{C}$

Ответ: $50,64 \mathrm{~m}^{3} /$ ч.

Задача 3

Определить усилие, которое развивает судовой гидравлический пресс, имеющий $\mathrm{d}_{2}=$ $250 \mathrm{мm}, \mathrm{d}_{1}=25 \mathrm{мм}, \mathrm{a}=1 \mathrm{м} \mathrm{и} \mathrm{b}=0,1 \mathrm{M}$, если усилие, приложенное к рукоятке рычага рабочим, $\mathrm{N}=200$ Н, а КПД равен 0,8 .

Ответ: 176 кН

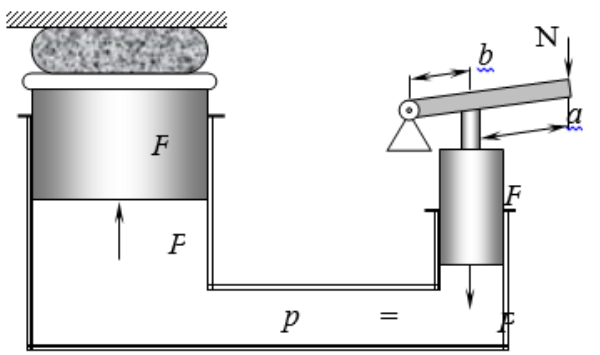

Рисунок 1 - Судовой гидравлический пресс.

\section{Задача 4}

Определить плотность батискафа $\rho$, плавающего в жидкостях, при полном погружении, если центр тяжести батискафа лежит в плоскости

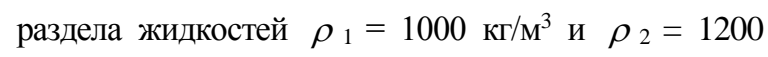
$\kappa \Gamma / \mathrm{M}^{3}$.

Ответ: $1100 \kappa г / \mathrm{M}^{3}$. 


\begin{tabular}{l|lrl|l|ll} 
& ISRA (India) & $=\mathbf{1 . 3 4 4}$ & SIS (USA) & $=\mathbf{0 . 9 1 2}$ & ICV (Poland) & $=\mathbf{6 . 6 3 0}$ \\
Impact Factor: & ISI (Dubai, UAE) $=\mathbf{0 . 8 2 9}$ & PUHU (Russia) $=\mathbf{0 . 2 3 4}$ & PIF (India) & $=\mathbf{1 . 9 4 0}$ \\
& GIF (Australia) & $\mathbf{0 . 5 6 4}$ & ESJI (KZ) & $=\mathbf{3 . 8 6 0}$ & IBI (India) & $\mathbf{4 . 2 6 0}$
\end{tabular}

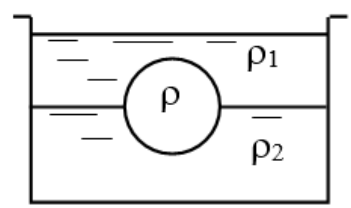

Рисунок 2 - Батискаф.

\section{Задача 5}

Судовой гидромультипликатор служит для повышения давления $p_{1}$, передаваемого насосом или аккумулятором давления. Определить давление $p_{2}$ при следующих данных: $G=3$ кН, $D$ $=125 \mathrm{mм}, p_{1}=100 \mathrm{H} / \mathrm{cm}^{2}, d=50 \mathrm{мм}$. Силами трения в уплотнениях пренебречь.

Ответ: $472,2 \mathrm{H} / \mathrm{cm}^{2}$

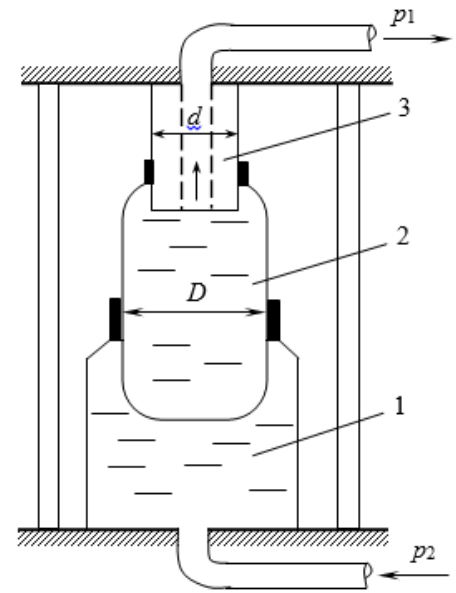

Рисунок 3 - Судовой гидромультипликатор.

\section{Задача 6}

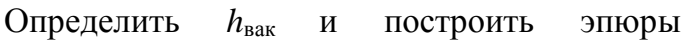
вакууметрического и абсолютного давлений на стенку судового водяного вакууметра, если $p_{\text {абс }}=$ $0,85 \cdot 10^{5}$ Па, а в нижнем резервуаре вода.

Ответ: 1,34 м

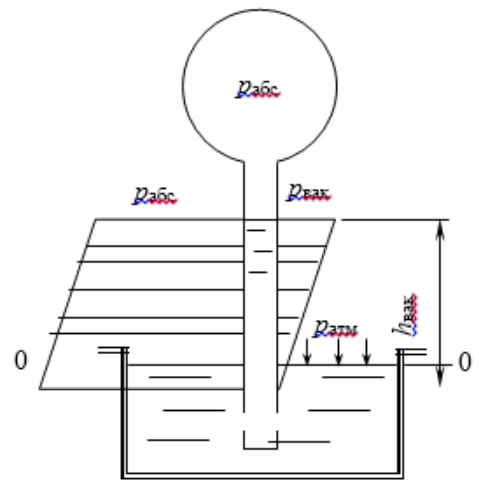

Рисунок 4 - Судовой водяной вакууметр.

Задача 7

Определить показания жидкостного манометра, присоединенного к резервуару с водой, на глубине $h=1 \mathrm{M}$, если по показаниям пружинного манометра давление $p_{\mathrm{M}}=0,25 \cdot 10^{5}$ Па

Ответ: 3,54 м 


\begin{tabular}{l|lrl|l|ll} 
& ISRA (India) & $=\mathbf{1 . 3 4 4}$ & SIS (USA) & $=\mathbf{0 . 9 1 2}$ & ICV (Poland) & $=\mathbf{6 . 6 3 0}$ \\
Impact Factor: & ISI (Dubai, UAE) $=\mathbf{0 . 8 2 9}$ & PUHU (Russia) $=\mathbf{0 . 2 3 4}$ & PIF (India) & $=\mathbf{1 . 9 4 0}$ \\
& GIF (Australia) & $\mathbf{0 . 5 6 4}$ & ESJI (KZ) & $=\mathbf{3 . 8 6 0}$ & IBI (India) & $\mathbf{4 . 2 6 0}$
\end{tabular}

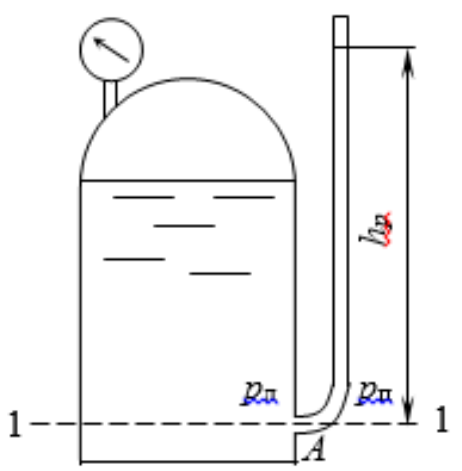

Рисунок 5 - Судовой жидкостный манометр.

\section{Задача 8}

Определить силу, точку приложения и направление ее действия, если вода действует на гидрозатвор диаметром $D=2$ м, шириной $B=3$ м.

Ответ: 1. Сила, действующая на вертикальную проекцию, $P_{x}=58.86$ кН

2. Вертикальная составляющая силы: $P_{z}=4623$ кН.
3. Полная сила гидростатического давления: $P=74,84$ кН.

4. Угол наклона результирующей силы с горизонтальной осью: $\alpha=30^{\circ} 15^{\prime}$. Сила $P$ проходит через центр окружности и приложена в точке $D$.

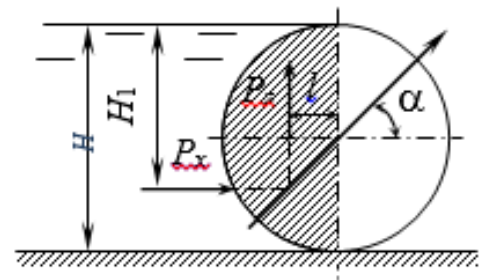

Рисунок 6 - Судовой гидрозатвор.

\section{Задача 9}

Определить минимально необходимый диаметр шарового поплавка, обеспечивающего автоматическое закрытие судового клапана при наполнении резервуара, если вода под давлением $p=24,5 \cdot 10^{4}$
Па заполняет резервуар через трубу диаметром $d=15$ мм, при $a=15$ мм и $b=500$ мм. Собственной массой рычага, клапана и поплавка пренебречь.

Ответ: $d=112$ мм .

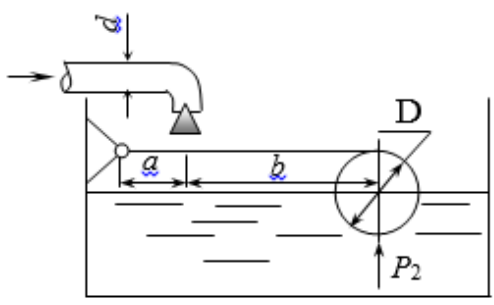

Рисунок 7 - Судовой клапан.

\section{Задача 10}

При анализе судовых систем применяется водомер Вентури, который представляет собой короткий отрезок трубы с сужением посредине. В широкой части и горловине устанавливаются пьезометры или дифференциальный манометр.
По данным рисунка определить действительный расход водомера.

Ответ:

$$
Q=\omega_{1} \omega_{2} \sqrt{\frac{2 g}{\omega_{1}^{2}-\omega_{2}^{2}}} \sqrt{h}
$$




\begin{tabular}{l|lrl|l|ll} 
& ISRA (India) & $=\mathbf{1 . 3 4 4}$ & SIS (USA) & $=\mathbf{0 . 9 1 2}$ & ICV (Poland) & $=\mathbf{6 . 6 3 0}$ \\
Impact Factor: & ISI (Dubai, UAE) $=\mathbf{0 . 8 2 9}$ & PUHU (Russia) $=\mathbf{0 . 2 3 4}$ & PIF (India) & $=\mathbf{1 . 9 4 0}$ \\
& GIF (Australia) & $\mathbf{0 . 5 6 4}$ & ESJI (KZ) & $=\mathbf{3 . 8 6 0}$ & IBI (India) & $\mathbf{4 . 2 6 0}$
\end{tabular}

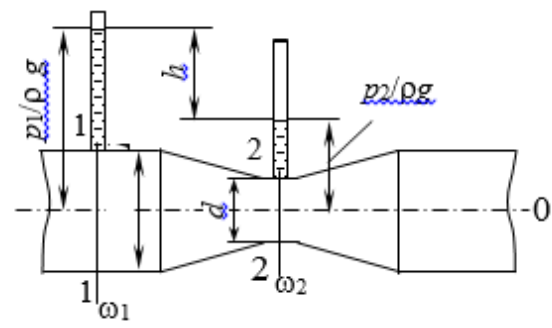

Рисунок 8 - Судовой водомер Вентури.

\section{Задача 11}

Карбюратор судовых поршневых двигателей внутреннего сгорания служит для осуществления подачи бензина и смешения его с потоком воздуха. Поток воздуха, засасываемый в двигатель, сужается там, где установлен распылитель бензина. Скорость воздуха в этом сечении возрастает, а давление по уравнению Бернулли падает. Найти соотношение между весовым расходом бензина $G_{6}$ и воздуха $G_{\text {в }}$ при заданных размерах $D$ и $d$ и коэффициентах сопротивления

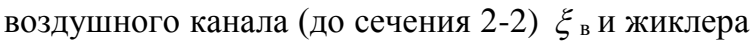
$\xi_{\text {ж . }}$

Ответ: $\frac{G_{\bar{\sigma}}}{G_{\mathrm{B}}}=\left(\frac{d}{D}\right)^{2} \sqrt{\frac{\rho_{\bar{\sigma}}\left(1+\xi_{\mathrm{B}}\right)}{\rho_{\mathrm{B}}\left(1+\xi_{\text {K }}\right)}}$

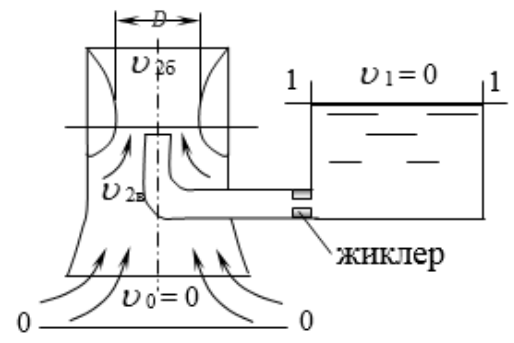

Рисунок 9 - Судовой карбюратор.

Задача 12

Трубка Пито в судовых системах применяется для измерения скорости воды и газа. Определить скорость потока в данных условиях чертежа.

Ответ: $v=\sqrt{2 g h_{v}}$.

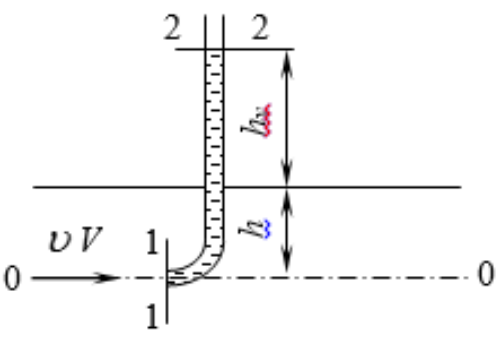

Рисунок 10 - Судовая трубка Пито.

\section{Задача 13}

Определить режим движения жидкости в судовом канале прямоугольной формы высотой 0,2 м и шириной 0,5 м при уровне воды 0,15 м и скорости $v=1,2 \mathrm{~m} / \mathrm{c}$.

Ответ: $\operatorname{Re}=450000$.

Так как $R e>\operatorname{Re}_{\text {кр }}=580$, то режим движения потока будет турбулентным. 


\begin{tabular}{l|lrl|l|ll} 
& ISRA (India) & $=\mathbf{1 . 3 4 4}$ & SIS (USA) & $=\mathbf{0 . 9 1 2}$ & ICV (Poland) & $=\mathbf{6 . 6 3 0}$ \\
Impact Factor: & ISI (Dubai, UAE) $=\mathbf{0 . 8 2 9}$ & PUHU (Russia) $=\mathbf{0 . 2 3 4}$ & PIF (India) & $=\mathbf{1 . 9 4 0}$ \\
& GIF (Australia) & $\mathbf{0 . 5 6 4}$ & ESJI (KZ) & $=\mathbf{3 . 8 6 0}$ & IBI (India) & $\mathbf{4 . 2 6 0}$
\end{tabular}

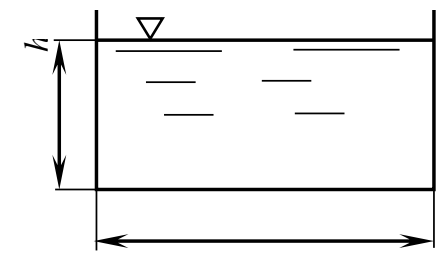

Рисунок 11 - Судовой канал.

\section{Задача 14}

Определить режим движения и потери напора по длине судового трубопровода, если длина судового трубопровода $100 \mathrm{м}$, диаметр $d=$ $100 \mathrm{мм}, Q=10$ л $/ \mathrm{c}, v_{\text {ж }}=0,726 \mathrm{~cm}^{2} / \mathrm{c}$.
Oтвет: $\mathrm{Re}=1750$.

Так как число Рейнольдса меньше 2320, то режим движения ламинарный.

Потери напора $h_{v}=3 \mathrm{M}$.

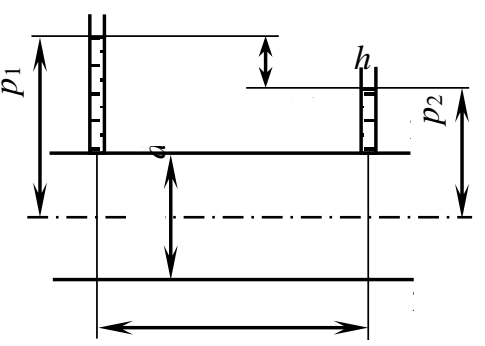

Рисунок 11 - Судовой трубопровод.

\section{Задача 15}

Определить потери давления при внезапном расширении судовых трубопроводов, применяемых в качестве нагревательных приборов системы судового отопления. Стояк, подводящий нагретую воду, и соединительные судовые трубы выполнены диаметром $d=0,025$ м и приварены к торцу труб $d_{1}=100$ мм. Скорость воды в подводящих трубах $v=0,3 \mathrm{~m} / \mathrm{c}, \quad$ а температура воды $t=80^{\circ} \mathrm{C}$.

Ответ: $\Delta \mathrm{P}=41,8$ Па.

\section{Задача 16}

Вода попадает в трюм из малой пробоины в вертикальном корпусе судна при постоянном напоре $H$. Высота положения отверстия над дном трюма $\Delta z=1,0$ м и достигает поверхности дна трюма на расстоянии $\ell=1,2$ м. Диаметр отверстия $d=50$ мм, $\varphi=0,97$. Определить скорость затопления трюма.

Ответ: $Q=28 \cdot 10^{-4} \mathrm{~m}^{3} / \mathrm{c}$.

\section{Задача 17}

Давление жидкости в первом трюме $p_{1}=2 \cdot 10^{5}$ Па, а во втором трюме $p_{2}=1,7 \cdot 10^{5}$ Па, $\mu=0,62$. Определить скорость затопления второго трюма относительно первого, если диаметр пробоины в вертикальной переборке $d=0,2$ мм, высота $H_{1}=7 \mathrm{M}$, $H_{2}=6 \mathrm{M}$.

Ответ: $Q=0,0175 \mathrm{~m}^{3} / \mathrm{c}$.

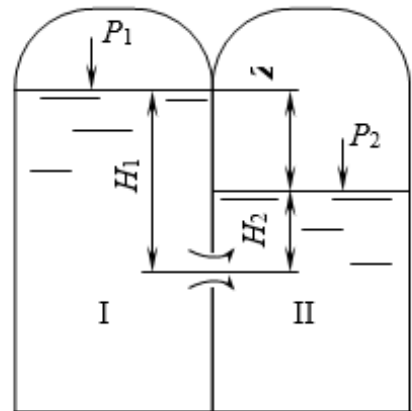

Рисунок 12 - Система судовых трюмов. 


\begin{tabular}{|c|c|c|c|c|c|c|}
\hline Impact Factor: & $\begin{array}{l}\text { ISRA (India) } \\
\text { ISI (Dubai, UAE } \\
\text { GIF (Australia) } \\
\text { JIF }\end{array}$ & $\begin{array}{l}=1.344 \\
=0.829 \\
=0.564 \\
=1.500\end{array}$ & $\begin{array}{l}\text { SIS (USA) } \\
\text { PИНЦ (Russia) } \\
\text { ESJI (KZ) } \\
\text { SJIF (Morocco) }\end{array}$ & $\begin{array}{l}=0.912 \\
=0.234 \\
=3.860 \\
=\mathbf{2 . 0 3 1}\end{array}$ & $\begin{array}{l}\text { ICV (Poland) } \\
\text { PIF (India) } \\
\text { IBI (India) }\end{array}$ & $\begin{array}{l}=6.630 \\
=1.940 \\
=4.260\end{array}$ \\
\hline
\end{tabular}

\section{Задача 18}

Определить скорость затопления трюма забортной водой и её скорость через круглую пробоину диаметром $d=0,2$ м, если $H=4$ м, $\mu=$ $0,62, \varphi=0,97$. Скоростным напором пренебречь.

Ответ: $8,58 \mathrm{~m} / \mathrm{c} .0,172 \mathrm{~m}^{3} / \mathrm{c}$.

\section{Задача 19}

Определить расход и скорость истечения воды из круглого отверстия диаметром $d=0,01$ м в боковой стенке судового накопителя пресной воды. Напор воды над центром отверстия $H=1 \mathrm{M}$, температура воды $t=20{ }^{\circ} \mathrm{C}\left(v=10^{-6} \mathrm{M}^{2} / \mathrm{c}\right)$.

Ответ:

$$
v=\varphi \sqrt{2 g H}=0,95 \sqrt{2 \cdot 9,81 \cdot 1}=4,2 \mathrm{M} / \mathrm{c} .
$$

$Q=\mu \omega \sqrt{2 g H}=0,62 \frac{\pi 0,01^{2}}{4} \sqrt{2 \cdot 9,81 \cdot 1} \approx 0,2 \cdot 10^{-3}$ $\mathrm{M}^{3} / \mathrm{c}$.

\section{Задача 20}

Определить диаметры: в начале и в конце судового водовыпуска, имеющего форму конически расходящегося насадка, работающего в затопленном режиме, если $Q=0,5 \mathrm{~m}^{3} / \mathrm{c},: \mu=$ $0,5, z=0,25$ м, длина насадка $\ell=4$ м.

$$
\begin{aligned}
& D=\sqrt{\frac{4 Q}{\pi \mu \sqrt{2 g z}}}=\sqrt{\frac{4 \cdot 0,5}{\pi \cdot 0,5 \sqrt{2 \cdot 9,81 \cdot 0,25}}}=0,76 \\
& d=D-2 \ell \operatorname{tg} \frac{\theta}{2} \approx 0,33 \mathrm{M} .
\end{aligned}
$$

Расход воды

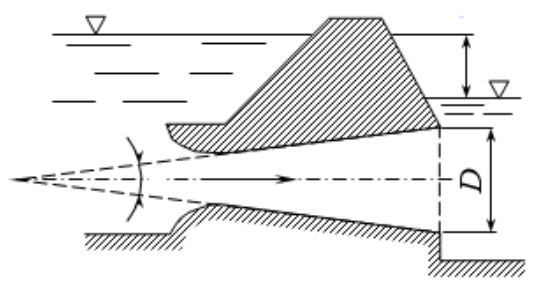

Рисунок 13 - Судовой водовыпуск.

\section{Задача 21}

В судовом трубопроводе по стальной трубе диаметром $d=500$ мм и толщиной стенок $\delta=10$ мм подается вода со скоростью 2,5 м/с. Пьезометрический напор перед открытой задвижкой равен 4 Ом. Определить повышение давление при быстром закрытии задвижки и полный напор $H$.

Ответ: повышение давления равно:

$$
\Delta p=\rho C_{v} v_{0}=1000 \cdot 1391 \cdot 2,5=3,48 \text { МПа }
$$

напор равен: $\Delta H=\frac{\Delta p}{\rho g}=\frac{3,48 \cdot 10^{6}}{9,81 \cdot 10^{3}} \approx 355$ м.

\section{Задача 22}

Определить расход в напорном судовом трубопроводе гидротарана, если рабочий расход $Q=30$ л/с, напор $H=3$ м, высота подачи $h=21 \mathrm{м}$, КПД $=0,6$.
Ответ: расход равен:

$$
q=\frac{\eta H Q}{(h-H)+\eta H}=\frac{0,6 \cdot 3 \cdot 30}{(21-3)+0,6 \cdot 3}=2,74 \pi / \mathrm{c} .
$$

перелив через клапан равен:

$$
Q-q=30-2,74=27,26 \text { л } / \mathrm{c} .
$$

\section{Задача 23}

Для получения технической воды в морском порту применяется земляная плотина. Определить точку высачивания $Z$ и фильтрационный расход $q$ через однородную земляную плотину $H=27 \mathrm{~m} ; b=14,5 \mathrm{~m} ; m_{1}=3 \mathrm{м}$; $m_{2}=2,5$ м, если $h_{в б}=25 \mathrm{м}, h_{н б}=4 \mathrm{м}$. Коэффициент фильтрации плотины $k=0,0002 \mathrm{~m} / \mathrm{c}$. Плотина построена на водонепроницаемом основании.

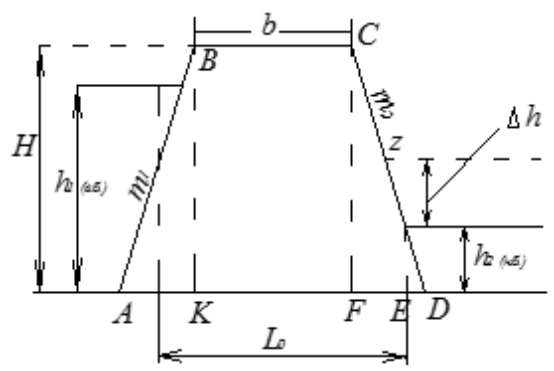

Рисунок 13 - Портовая земляная плотина. 


\begin{tabular}{|c|c|c|c|c|c|c|}
\hline Impact Factor: & $\begin{array}{l}\text { ISRA (India) } \\
\text { ISI (Dubai, UAE } \\
\text { GIF (Australia) } \\
\text { JIF }\end{array}$ & $\begin{array}{l}=1.344 \\
=0.829 \\
=0.564 \\
=1.500\end{array}$ & $\begin{array}{l}\text { SIS (USA) } \\
\text { PИНЦ (Russia) } \\
\text { ESJI (KZ) } \\
\text { SJIF (Morocco) }\end{array}$ & $\begin{array}{l}=0.912 \\
=0.234 \\
=3.860 \\
=\mathbf{2 . 0 3 1}\end{array}$ & $\begin{array}{l}\text { ICV (Poland) } \\
\text { PIF (India) } \\
\text { IBI (India) }\end{array}$ & $\begin{array}{l}=6.630 \\
=1.940 \\
=4.260\end{array}$ \\
\hline
\end{tabular}

Ответ: точка высачивания $\Delta h=5,3 \mathrm{~m}$; равен:

фильтрационный расход через плотину

$q=k \frac{\Delta h}{m_{2}}\left(1+2,3 \cdot \lg \frac{h_{\mu \sigma}+\Delta h}{\Delta h}\right)=0,0002 \frac{5,3}{2,5}\left(1+2,3 \cdot \lg \frac{4+5,3}{5,3}\right)=0,00028 \cdot m / c$

\section{Задача 24}

В районе морского порта фильтрационный поток движется равномерно на глубине $h_{0}=3,5 \mathrm{M}$. Уклон дна подстилающего слоя $i=0,0015$, а коэффициент фильтрации $k=0,008 \mathrm{M} / \mathrm{c}$. Определить расход воды на одном метре фильтрующего потока.

Ответ: расход воды на одном метре фильтрующего потока: $q=k \cdot h_{0} \cdot i=0,008 \cdot 3,5 \cdot 0,0015=4,2 \cdot 10^{-5} \mathrm{M}^{3} /(c \cdot M)$

\section{Задача 25}

Определить коэффициент фильтрации грунта в районе морского порта при равномерном движении грунтового потока, при уклоне подстилающего водонепроницаемого слоя $i=0,05$, удельном расходе $q=0,025 \cdot 10^{-3} \mathrm{~m}^{3} / \mathrm{c}$ и глубине потока $\mathrm{h}=3 \mathrm{~m}$.

Ответ: коэффициента фильтрации равен:

$$
k=\frac{q}{h_{0} i}=\frac{0,025 \cdot 10^{-3}}{0,05 \cdot 3}=0,167 \cdot 10^{-3} \mathcal{M} / \mathrm{C}
$$

\section{Задача 26}

Определить коэффициент фильтрации $k$, если в районе морского порта в полевых условиях были получены следующие данные:

1) время появления воды в шурфе 2 от начала исследования составило 45 часов;

2) разность отметок в рабочем шурфе 1 и наблюдаемом шурфе $2 H=4$ м;

3) расстояние между стенками наблюдаемого и рабочего шурфа $\mathrm{L}=5 \mathrm{M}$;

4) пористость грунта $m=0,45$

\section{Рисунок 14 - Система фильтрации почвы.}

Ответ: коэффициента фильтрации равен:

$$
k=\frac{L^{2} m}{T\left(\nabla_{1}-\nabla_{2}\right)}=\frac{5^{2} \cdot 0,45}{45 \cdot 3600 \cdot 4}=2,78 \cdot 10^{-4} \mathrm{M} / \mathrm{C}
$$

\section{Задача 27}

Земснаряд вынимает 500 м $^{3}$ грунта в час. Объем пульпы (грунт, смешанный с водой) в 10 раз больше объема грунта. Какова скорость движения пульпы в трубе диаметром 0,6 м?

Ответ: 4,9 м/с.

\section{Задача 28}

Определить диаметр сливного отверстия судового цилиндрического танка, чтобы из него вытекало 77000 кг/час лёгкой нефти плотностью 865 кг/м ${ }^{3}$. Напор Н нефти постоянен и равен 12 метров.

Ответ: $50 \mathrm{Mм}$

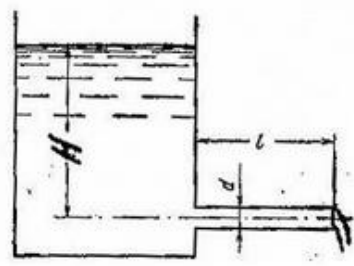

Рисунок 15 - Судовой цилиндрический танк.

\section{Задача 29}

Батискаф всплывает с постоянной скоростью $v$ в море. Плотность морской воды, в момент всплытия, в 4 раза больше плотности материала батискафа. Во сколько раз сила трения $\mathrm{F}_{\mathrm{Tp}}$, действующая на всплывающий батискаф, больше силы тяжести $\mathrm{mg}$, действующей на этот батискаф?

Ответ: в 3 раза

Задача 30 
В районе морского порта в водопроводной трубе образовалось отверстие сечением $4 \mathrm{mм}^{2}$, из второго бьет вертикально вверх струя воды, поднимаясь на высоту 80 см. Какова утечка воды за сутки?

\section{Ответ: 1380 л.}

\section{Conclusion}

Представленный метод формирования широкопрофильного профессионального мышления связывается с многозначным проявлениемпедагогометрической эрцгаммности. Представление системных гидравлических задач прикладной физики морского флота педагогометрического анализа отражает основные направления развития и совершенствования базы данных педагогометрических моделей образовательных объектов относительно педагогометрического математического моделирования учебного процесса. Это связывается с процессами совершенствования программируемых математических моделей учебной деятельности относительно характера представления критериев жизнедеятельности, цикличности, системности и этапности, которые образуют базисную ячейку образовательного пространства, определяют условия развития абсолютного образовательного цикла, отражающего специфическую структуру подготовки широкопрофильных специалистов при реализации международных образовательных стандартов эревнометрического содержания.

\section{References:}

1. Mishchik SA (2014) Pedagogometrika and mathematical modeling educational activity. Materialy Mezhdunarodnoy nauchnoy konferenctsii "Modern mathematics in science" - 30.06.2014. ISJ Theoretical \&Applied Science 6(14): 54-56 Caracas, Venezuela. doi: http://dx.doi.org/10.15863/TAS.2014.06.14.10

2. Mishchik SA (2014) Simulation training activity methods of mathematical logic. Materialy Mezhdunarodnoy nauchnoy konferenctsii "Eurapean Science and Education" - 30.07.2014. ISJ Theoretical \&Applied Science 7(15): 72-74 Marseille, France. doi: http://dx.doi.org/10.15863/TAS.2014.07.15.13

3. Mishchik SA (2014) Mathematical modeling system integrity-cycle of life activity - first goal pedagogometriki. Materialy Mezhdunarodnoy nauchnoy konferenctsii "European Applied Sciences" - 30.08.2014. ISJ Theoretical \&Applied Science 8(16): 77-79. Aix-en-Provence, France. doi: http://dx.doi.org/10.15863/TAS.2014.08.16.13

4. Mishchik SA (2014) Mathematical modeling system integrity-curricular activities - the second problem pedagogometriki. Materialy Mezhdunarodnoy nauchnoy konferenctsii "European Innovation" - 30.09.2014. ISJ Theoretical \&Applied Science 9(17): 126-128 Martigues, France. doi: http://dx.doi.org/10.15863/TAS.2014.09.17.21

5. Mishchik SA (2014) Mathematical modeling holistic-systemic communicative activity - the third task pedagogometriki. Materialy Mezhdunarodnoy nauchnoy konferenctsii "European Scientific Achievements" 30.10.2014. ISJ Theoretical \&Applied Science
10(18): 45-47 Brighton, UK. doi: http://dx.doi.org/10.15863/TAS.2014.10.18.11

6. Mishchik SA (2014) Mathematical modeling integrity - system performance subject - fourth task pedagogometriki. Materialy Mezhdunarodnoy nauchnoy konferenctsii "Eurapean Science and Technology" 30.11.2014. ISJ Theoretical \&Applied Science 11(19): 51-54 Southampton, UK. doi: http://dx.doi.org/10.15863/TAS.2014.11.19.10

7. Mishchik SA (2015) Pedagogometrik - science and academic subject. Materialy Mezhdunarodnoy nauchnoy konferenctsii "European Technology in Science" 28.02.2015. ISJ Theoretical \& Applied Science 02 (22): 103-106 Malmö, Sweden. doi: http://dx.doi.org/10.15863/TAS.2015.02.22.17

8. Simakin VI, Goreshnik ID, Kordon MY (2005) Gidravlika. Penza. - p.188

9. Tokmazov GV (2014) Matematicheskoe modelirovanie $\mathrm{v}$ uchebno-professional'noy deyatel'nosti. Materialy Mezhdunarodnoy nauchnoy konferentsii «Modern mathematics in science» - 30.06.2014. ISJ Theoretical \& Applied Science 6(14): 44-46. - Caracas, Venezuela. doi: http://dx.doi.org/10.15863/TAS.2014.06.14.8

10. Tokmazov GV (2014) Mathematical modeling research skills in educational activity methods of probability theory. Materialy Mezhdunarodnoy nauchnoy konferenctsii "Eurapean Science and Technology" 30.11.2014. ISJ Theoretical \&Applied Science 11(19): 66-69 Southampton, United Kingdom. doi:

http://dx.doi.org/10.15863/TAS.2014.11.19.13 